\title{
Virus orf en humanos, confirmación molecular de un caso clínico en Chile
}

\author{
Carlos Flores, Erika González, Andrea Verna, Andrea Peralta, Carolina Madariaga, \\ Anselmo Odeón y Germán Cantón
}

\section{Orf virus in human, confirmation in case report from Chile}

Infection with the orf virus, also known as contagious ecthyma, is recognized as an occupational zoonosis worldwide. It is diagnosed by cutaneous lesions that progress rapidly from macules to papules, vesicles and pustules. The clinical case of a student of veterinary medicine who had had contact with goats, clinically healthy and without apparent lesions, which occured 19 days ago, is reported. She presented two vesicular lesions that coalesced to form a larger lesion surrounded by an erythematous halo. The lesions were compatible with the classical presentation of those produced by the orf virus in humans. The presence of the orf virus was confirmed by a nested PCR from biopsy tissue. It is one of the first cases confirmed by molecular techniques in humans in Chile.

Key words: Contagious ecthyma; zoonosis; orf virus; PCR.

Palabras clave: Ectima contagioso; zoonótico; virus orf; reacción de polimerasa en cadena.

\section{Introducción}

$\mathrm{E}$ 1 virus orf pertenece a la familia Poxviridae y es uno de los cuatro miembros del género Parapoxvirus. Es el agente responsable del ectima contagioso (EC), una zoonosis ocupacional de distribución mundial. El virus orf tiene afinidad por rumiantes domésticos, tales como ovinos y caprinos; sin embargo, también se han comunicado casos en especies silvestres ${ }^{1}$. En seres humanos, el virus del EC puede ser adquirido por grupos de riesgo, en que se incluyen a médicos veterinarios, técnicos veterinarios, carniceros, pastores, esquiladores, personal de frigorífico, personal de faena, laboratoristas, empacadores de carnes frías y trabajadores relacionados al rubro caprino y ovino ${ }^{2,3}$. También se ha asociado a pacientes con enfermedades inmunosupresoras como la infección por VIH y la enfermedad de $\mathrm{Crohn}^{2-4}$, enfermedades autoinmunes como la esclerodermia ${ }^{5} \mathrm{y}$ a pacientes sometidos a terapias inmunosupresoras, debido a una inhibición de citoquinas fundamentales en la defensa ante infecciones virales ${ }^{2,4,6,7}$. Por lo general las lesiones, tanto en animales como en seres humanos, son autolimitadas. Tiene un período de incubación de tres a siete días ${ }^{8}$, pudiendo variar de tres a seis semanas, dependiendo de su gravedad y el estado inmunitario del paciente ${ }^{9}$. Las lesiones típicas en los seres humanos ocurren en manos, brazos y ocasionalmente en el rostro. Han sido descrito casos más agresivos que pueden cursar con fiebre, linfangitis y lesiones de mayor tamaño, conocida como orf gigante, llegando a tener una duración de cuatro a cinco meses9. El cuadro clínico puede prolongarse por una sobreinfección bacteriana secundaria, lo que ha sido frecuentemente reportado ${ }^{8}$. Si bien, el EC es descrito en todo el mundo como una zoonosis ocupacional, los casos publicados por entidades oficiales probablemente no representen fehacientemente la situación actual de la enfermedad. Algunos países donde se han confirmado y comunicado casos de EC en seres humanos son Australia ${ }^{5}$, Chile $^{10}$, Brasil $^{11}$, Grecia $^{12}$, México $^{3,9}$, E.U.A ${ }^{8,13}$, Noruega ${ }^{2}$, Inglaterra ${ }^{14}$, Bélgica ${ }^{4}$, Turquía ${ }^{15}$ y Nueva Zelanda ${ }^{16}$. Presentamos el caso clínico de una estudiante de medicina veterinaria, de 21 años, con una infección por el virus orf confirmado por diagnóstico molecular, segundo caso reportado en Chile.

\section{Caso clínico}

Mujer de 21 años, previamente sana, estudiante de medicina veterinaria, que sin utilizar medidas mínimas de bioseguridad, sufrió accidentalmente una laceración en el dedo anular de su mano derecha al ser golpeada con la cornamenta de un caprino. El hecho ocurrió en la comuna de San Bernardo, Región Metropolitana, Chile. Los animales se encontraban clínicamente sanos y sin evidencia de enfermedades en los últimos meses. Diecinueve días posterior a esta actividad, la estudiante presentó en el mismo sitio dos pequeñas lesiones, en un principio bien definidas e independientes, con un halo eritematoso, que posteriormente coalescieron formando una vesícula única. Se realizó seguimiento clínico desde el día 19 post-contacto con los animales (Figura 1-A) hasta el día 43 (Figura 1-B). Hasta 30 días post-
Universidad Mayor. Santiago, Chile. Facultad de Ciencias (CF). Instituto Nacional de Tecnología Agropecuaria (INTA), Balcarce, Buenos Aires, Argentina ( $E G, A V, A O, G C$ ). Centro de Investigación en Ciencias Veterinarias $y$ Agronómicas (CICVyA), INTA Castelar, Argentina (AP). Universidad Santo Tomás. Santiago, Chile. Facultad de Recursos Naturales y Medicina Veterinaria $(\mathrm{CM})$

Sin conflictos de interés entre los autores ni fuentes de financiamiento externas.

Recibido: 9 de mayo de 2017 Aceptado: 19 de octubre de 2017

Correspondencia a: Carlos Flores carlos.flores@umayor.cl 


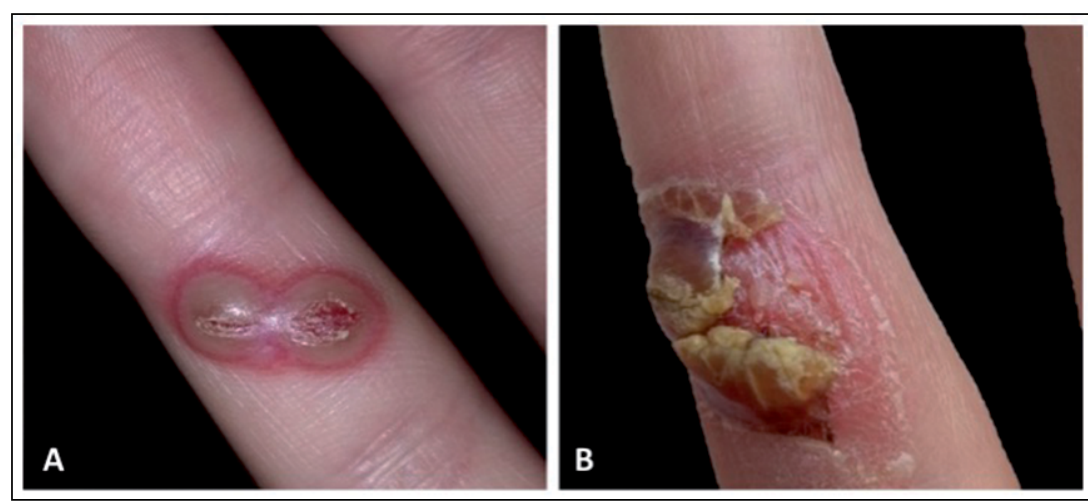

Figura 1 A-B. Lesión por virus orf en dedo anular de una joven de 21 años. A: Día 19 post-contacto con caprinos: vesículas coalescentes formando una lesión única rodeada de un halo eritematoso y vesículas turgentes al tacto. B: Día 43 post-contacto con caprinos: lesión con centro necrótico amarillo grisáceo, rodeado de costras secas; bajo esta lesión se observa tejido de granulación.

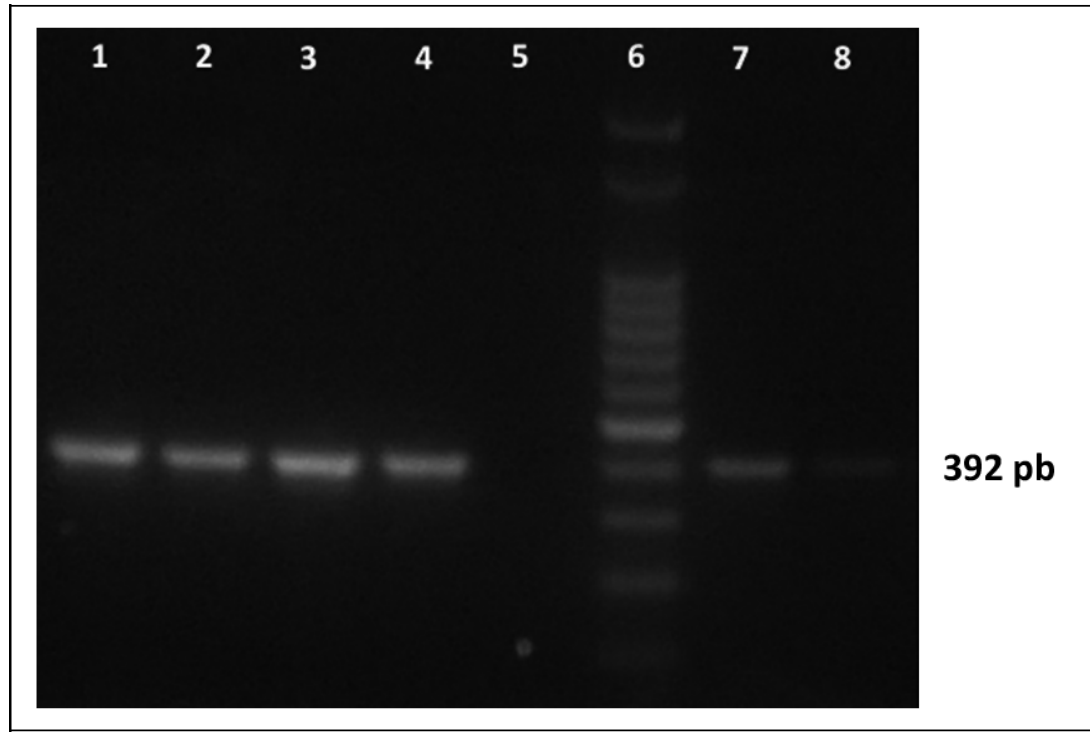

Figura 2. Amplificación del gen ORF045 (392 PB) en dos muestras obtenidas de costra seca en lesión (EC1 y EC2): carril 1: EC1 (ADN puro), carril 2: EC1 (ADN 1:10), carril 3: EC2 (ADN puro), carril 4: EC2 (ADN 1:10), carril 5: control negativo, carril 6: marcador de peso molecular, carril 7 : control positivo 1 (ADN puro), carril 8: control positivo 1 (ADN 1:10)

contacto con los animales, las lesiones fueron descritas como pruriginosas, eritematosas, turgentes, dolorosas e incómodas. Posteriormente se produjo una linfangitis secundaria, que limitaba la movilidad de la extremidad afectada. Al resecar la lesión cutánea mostró un centro necrótico amarillo grisáceo y bajo ella, la formación de tejido de granulación. Las lesiones fueron evaluadas por un dermatólogo, que las describió como compatibles con un EC. No se realizaron exámenes complementarios y el tratamiento realizado se enfocó en el manejo del dolor, mediante el uso de antinflamatorios no esteroidales. En forma paralela, se obtuvieron muestras de especímenes de costra seca de las lesiones cutáneas, las que fueron congeladas y analizadas en el Laboratorio de Virología del Instituto Nacional de Tecnología Agropecuaria, Balcarce, Buenos Aires, Argentina. Se extrajo ADN mediante el uso del mini-kit QIAamp DNA (QIAGEN), siguiendo las instrucciones del laboratorio fabricante. Posteriormente se realizó una RPC anidada utilizando los partidores 045F y 045R siguiendo el protocolo de Kottaridi y cols., $2006^{17}$. Los oligonucleótidos amplificados corresponden a la región interna del gen ORF045 (posición pb 44-435). La secuenciación dio como resultado positivo a ADN del virus orf (Figura 2), confirmándose así un EC. La paciente evolucionó en forma satisfactoria con regresión completa de la lesión a las siete semanas, manteniendo un leve aumento de la sensibilidad local que duró varios meses.

\section{Discusión}

Si bien el EC, tanto en animales como en seres humanos, es una enfermedad autolimitada y que frecuentemente se realiza el diagnóstico de forma clínica, es indispensable poder realizar la confirmación diagnóstica mediante alguna de las técnicas disponibles (microscopía electrónica de transmisión, inmunohistoquímica y RPC). La histopatología también puede orientar al diagnóstico, observándose alteraciones características como queratinocitos intensamente vacuolizados con presencia de cuerpos de inclusión eosinofílicos intracitoplasmáticos, acantosis, formación de vesículas y degeneración hidrópica a nivel epitelial ${ }^{11}$. En este caso no fue posible realizar este análisis, debido al tamaño pequeño de las biopsias recolectadas y a la cronicidad de la lesión, lo que dificultó encontrar las alteraciones histopatológicas del EC. Su confirmación es importante debido a que dentro de los diagnósticos diferenciales se encuentra el ántrax cutáneo, o también conocido como carbunco, causado por el agente Bacillus anthracis. Este último también es una enfermedad zoonótica, de notificación obligatoria, y que en hasta $20 \%$ de los casos las lesiones se pueden diseminar por vía hematógena causando cuadros de septicemia con resultado fatal ${ }^{18}$. La evolución de nuestra paciente concuerda con lo descrito para el EC, tanto en el tiempo de incubación como en la duración del cuadro. La paciente no contaba con antecedentes de tratamientos farmacológicos que pudiesen haber generado una predisposición a este agente, además de no contar con una historia familiar de enfermedades inmunosupresoras o que favoreciera la replicación viral.

\section{Resumen}

La infección por el virus orf, también conocida como ectima contagioso, es reconocida una zoonosis ocupacional. Se diagnostica por lesiones cutáneas que evolu- 
cionan rápidamente desde máculas a pápulas, vesículas y pústulas. Se presenta el caso clínico de una estudiante de medicina veterinaria que había tenido contacto con caprinos, clínicamente sanos y sin lesiones aparentes, hacía 19 días. Presentó dos lesiones vesiculares que coalescieron hasta formar una lesión de mayor tamaño rodeada por un halo eritematoso. Las lesiones fueron compatibles con la presentación clásica de las producidas por el virus orf en humanos. Se confirmó la presencia del virus orf mediante una RPC anidada del tejido de biopsia. Es uno de los primeros casos confirmados mediante técnicas moleculares en seres humanos en Chile.

\section{Referencias bibliográficas}

1.- Vikøren T, Lillehaug A, Åkerstedt J, Bretten T, Haugum M, Tryland M. A severe outbreak of contagious ecthyma (orf) in a free-ranging musk ox (Ovibos moschatus) population in Norway. Vet Microbiol 2008; 127: 10-20.

2.- Rørdam O M, Grimstad Ø, Spigset O, Ryggen $\mathrm{K}$. Giant orf with prolonged recovery in a patient with psoriatic arthritis treated with etanercept. Acta Derm Venereol 2013; 93: 4878.

3.- Carrada B T. Dermatovirosis de Orf: investigación clínico-virológica y revisión bibliográfica. Dermatología Rev Mex 2005; 49: 69-74.

4.- Duchateau N C, Aerts O, Lambert J. Autoinoculation with Orf virus (ecthyma contagiosum. Int J Dermatol 2014; 53: e60-2.

5.- Maor D, Yu L L, Brand R. A case of orf disease in a patient with scleroderma. JAAD Case Rep 2017; 3: 155-7.

6.- Tórtora J L. Ectima contagioso en ovinos y caprinos. Tesis Doctoral. Facultad Cuautitlán UNAM, México 2014. Ciencia Veterinaria
4-1987: 257-88. Disponible en: http://www. fmvz.unam.mx/fmvz/cienciavet/revistas/ CVvol4/CVv4c9.pdf

7.- Turan E, Yesilova Y, Ucmak D. A case of orf (ecthyma contagiosum) with multiple lesions. J Pak Med Assoc 2013; 63: 786-7.

8.- Centers for Disease Control and Prevention (CDC). Human Orf virus infection from household exposures-United Sates, 2009-2011. MMWR Morb Mortal Wkly Rep 2012; 61: 245-8.

9.- Tórtora J L, González S, Hernández E. Lesiones por parapoxvirus en veterinarios de México. Vet Méx 1998; 29: 203-7.

10.- Cea M, Reyes E, Bravo A, Hojas R. Estandarización de una técnica molecular para el diagnóstico del virus orf útil en la ganadería ovina. Cien Trab 2008; 10 (28): 39-46.

11.- Nóbrega J, Macedo J, Araújo J, Dantas A, Soares M, Riet-Correa F. Ectima contagioso em ovinos e caprinos no semi-árido da Paraíba. Pesq Vet Bras 2008; 28: 135-9.

12.- Georgiades G, Katsarou A, Dimitroglou K. Human Orf (Ecthyma contagiosum). J Hand Surg Br 2005; 30: 409-11.
13.- Lederman E R, Tao M, Reynolds M G, Li Y, Zhao H, Smith S K, et al. An investigation of a cluster of parapoxvirus cases in Missouri, Feb-May 2006. Epidemiologic, clinical and molecular aspects. Animals (Basel) 2013; 3 : 142-57.

14.- Hodgson-Jones I S. Orf in London. Br Med J 1951; 1 (4710): 795-6.

15.- Karakas A, Oguzoglu T C, Coskun O, Artuk C, Mert G, Gul H C, et al. First molecular characterization of a Turkish orf virus strain from a human based on a partial B2L sequence. Arch Virol 2013; 158: 1105-8.

16.- Robinson A J, Petersen G V. Orf virus infection of workers in the meat industry. N Z Med J 1983; 96: 81-5.

17.- Kottaridi C, Nomikou K, Lelli R, Markoulatos P, Mangana O. Laboratory diagnosis of contagious ecthyma: comparison of different PCR protocols with virus isolation in cell culture. J Virol Methods 2006; 134: 119-24.

18.- Perret P, Maggi L, Pavletic C, Vergara R, Abarca K, Dabanch J, et al. Ántrax (carbunco). Rev Chilena Infectol 2001; 18: 291-99. 